\title{
Development of the Hydro Static Wind Turbine Powered RO System for Maximum Power Point and Maximum Permeate Flow Tracking
}

\author{
Foad Srhan Jiwad ${ }^{a *}$, Mojtaba Behnam Taghadosi ${ }^{a}$,Ahmed Abed Al-Kadhem Majhool ${ }^{b}$ \\ ${ }^{a}$ Electrical Engineering Department, Track Mechatronic, Imam Reza International, Mashhad, Iran \\ ${ }^{b}$ Faculty of Engineering - University of Al-Qadisiyah-Iraq
}

\section{ARTICLE INFO}

\section{Article history:}

Received 06 February 2020

Received in revised form 16 March 2020

Accepted 20 March 2020

\section{Keywords:}

Non-Desalination

Wind Turbine

Hydraulic Transition

Maximum Power Point Tracking

RO Module

Energy recovery

\begin{abstract}
A B S TR A C T
Wind energy is one of the cheapest sources of energy that may solve the Climate change problem and fresh water scarcity challenges. This article introduces a novel Desalination Wind Turbine that is cheaper and more efficient than the common wind turbine, especially offshore wind turbine. In this system, the wind energy transmitted to the water pump by a hydraulic transmission line. The RO module is used for fresh water production. The pressure recovery module is added to RO system, to increase the permeated flow. It can be increased the permeate flow up to $45 \%$, which is significant. The Maximum Power Point Tracking (MPPT) based on the hydraulic oil pressure measurement is implemented. In addition, the Maximum Permeate Flow Tracking control loop, similar to MPPT, is introduced to optimized the pressure of the RO system. It is increased the annual permeate production up to $8 \%$. The long term performance of the system, such as annual water production is calculated and the ability of the system to MPPT and the wind turbulence and gust is analyzed. The rotor speed overshoot of the closed loop system is less than $16 \%$, which is acceptable.
\end{abstract}

\section{Introduction}

Fresh water scarcity is one of the most challenging in the world now, and in the future [1,2]. The wastewater treatment and the seawater desalination plants are used to produce clean water [2]. Today, most of the desalination power plants are supported by fossil fuel power stations. This means, producing more fresh water causes more $\mathrm{CO}_{2}$ emission in the atmosphere. The reverse osmosis method is the most usual technology for producing clean water [3]. The RO system needs a high-pressure water pump (more than $30 \mathrm{bar}$ ) for producing fresh water from

Seawater [4]. The details for these systems are described in [5]. Usually, these systems need an electrical motor to drive a water pump. However, another solution is to drive the pump directly with a diesel engine or a hydraulic motor, which eliminates electrical generator and motor, and increased efficiency of the system. In this configuration the drive system and water pump should be near each other.

Another serious world challenge is climate change [1]. Currently, burning more fossil fuels for generating more electrical energy is not a good solution, because it will be accelerating Climate change phenomena. Therefore, Renewable energy powered desalination system is investigated [6] and it is very popular in the world, especially for the off grid systems.

Wind energy is one of the important sources of clean energy. A Wind Turbine converts wind energy to electrical energy. Wind powered desalination systems are presented in [7], which is described as the

* Corresponding author.

E-mail address: foad090@gmail.com (Foad Srhan Jiwad) 
principle, configurations, design, and implementation of these systems and their histories. Maskus Forstmeier and el.al feasibility study on a wind powered desalination project [8] Also Integrated wind energy desalination system is investigated by Niskayuna [9]. He developed the component models of the wind, wind turbine, RO modules and analyzed the cost of water, which is showed that the wind power desalination system has a potential to be viable. In, the above references, the wind energy is converted to the electrical energy to drive RO systems.

In classical wind turbine, and drive trains they consist of main shaft, gearbox, and couplings. Wind turbine gearboxes are expensive and its failure has a long down time [10]. An idea to solve this problem is the hydraulic transmission system [11,12]. These systems, consist of the hydraulic pump in the nacelle, a variable displacement motor, and the electrical generator at the ground and other auxiliary components. The details of these systems are described in [13, 14]. The main advantages are:

- Reduction of the nacelle Wight that can be reduced the tower weight and cost

- Easy maintenance of the generator and other components at the ground

These features are more valuable for float offshore wind turbine that light weight tower and nacelle caused a great reduction in the foundation costs [14].

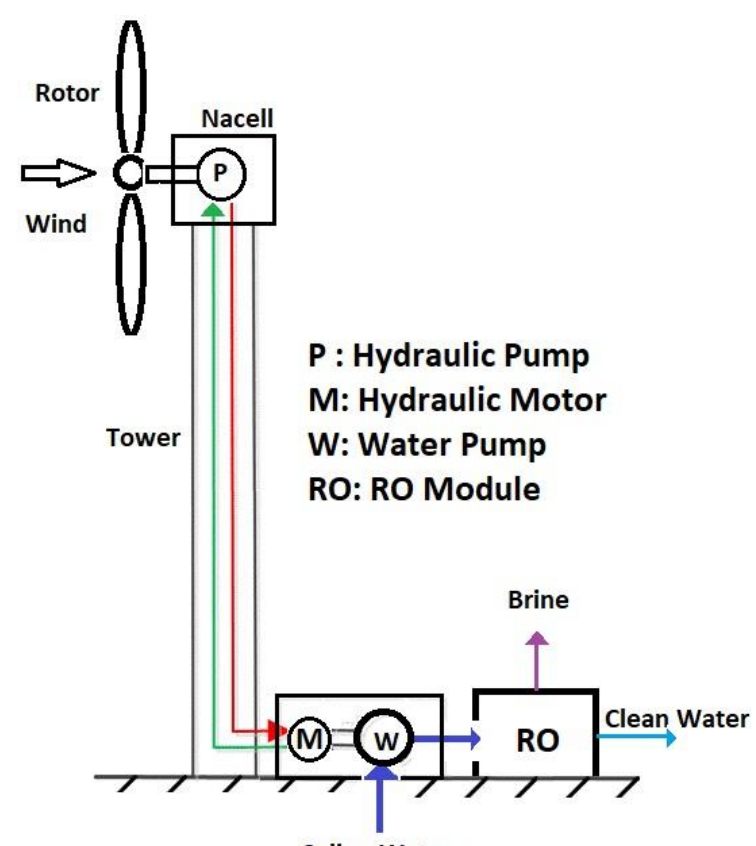

Saline Water

Figure 1: General View of the Desalination Wind Turbine

In this article an efficient desalination wind turbine is described which deals with the converted wind energy to the fresh water without producing electrical energy to avoid energy waste from the energy converter to boost efficiency and reduce the overall cost (See Fig. 1 for descriptions and schematic representation.). The main advantages of this concept are:

- Gearbox eliminating to decrease down time, nacelle weight and turbine cost, and increase efficiency of the drive train.

- Generator and convertor eliminating to decrease the nacelle weight and turbine cost and increase the efficiency of the power train.
- By Nacelle's weight reduction, the tower can be lighter, the foundation will be smaller, and the wind turbine cost will be decreased, especially for offshore wind turbine.

But, this system may have some challenges as follows:

- The controllability of the system and wind turbine performance in presents of the wind turbulence and wind speed sudden changes

- The increased cost for the hydraulic system, which is much less than the cost of the gearbox, generator, and convertor and heavy tower.

In the following sections, the desalination wind turbine is modeled and steady state behavior of the system for brackish water desalination and sea water desalination is analyzed. Also the controllability of the system is investigated.

\section{Desalination Wind Turbine modeling}

The fluid power transmission system, which is designed for wind turbine, has many details [15]. It is consisting of many check valves, pressure control valves, accumulators, etc. For describing the concept, the main components that have important functions in the dynamic response of the system are modeled, the model is shown in Fig. 2 below.

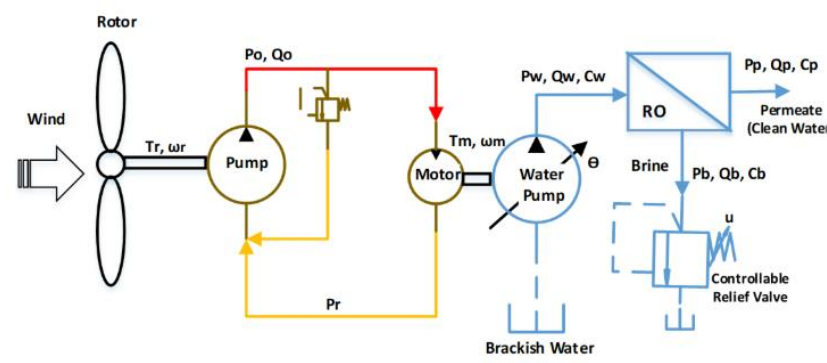

Figure 2: Desalination Wind Turbine Model for brackish water

The wind energy is converted to mechanical energy by Rotor. The rotor speed $\left(\omega_{r}\right)$ is a function of the Rotor torque $\left(T_{a}\right.$ )and hydraulic pump torque $\left(T_{r}\right)$ and based on the Newton second law, it can be written as [13]:

$T_{a}-T_{r}-B_{r} \omega_{r}=J_{r} \dot{\omega}_{r}$

The Rotor torque has a nonlinear and complex function as follows [10]:

$T_{a}=\operatorname{function}\left(\omega_{r}, \beta, V_{w}\right)$

$\beta$ is the pitch angle. The wind turbine specification is formed [16] and presented in Table 1 below. The other parameters are also defined in Table 1. More details of these equations can be found in [16].

\section{Table 1: Wind Turbine Specification [16]}

\begin{tabular}{ll}
\hline Rated Aerodynamic Power & $3600 \mathrm{~W}$ \\
Rotor Nominal Speed & $145 \mathrm{rpm}$ \\
Number of blades & 3 \\
Rotor Radius & $3.3 \mathrm{~m}$ \\
Tip Speed Ratio & 6.6 \\
\hline
\end{tabular}

The main shaft, which is connected to the Rotor, drives a hydraulic pump. The relation between pump and main shaft torque and speed can be defined as [11]: 
$T_{r}=D_{p}\left(P_{o}-P_{r}\right)$

$Q_{o}=D_{p} \omega_{r}$

$P o$ is the hydraulic high pressure and $P r$ is the hydraulic low pressure which is considered to be zero. The pressurized oil, transmitted energy to the hydraulic variable displacement motor. The relations are presented in equations (5) and (6) [11]. The water pump is driven by this motor, and pressurized seawater. By neglecting these pump and motor inertia, compare to the wind rotor moment of inertia, the second newton law for hydraulic motor can be written as Eq. (5) and (6) and for water pump can be written as Eq. (7) and (8) [11]:

$T_{m}=D_{m} \theta\left(P_{o}-P_{r}\right)$

$Q_{o}=D_{m} \theta \omega_{m}$

$T_{w}=D_{w} P_{w}$

$Q_{w}=D_{w} \omega_{m}$

The $\theta$ is the motor angular that varies from 0 to one and is related to the swash plate angle. The $P W$ is set by the brine relief valve and is a design parameter and constant. By using Eqs. (1) to (8), the dynamic relation of the wind turbine is:

$T_{a}-P_{w} \frac{D_{p}}{D_{m}} D_{w} \theta-B_{r} \omega_{r}=J_{r} \dot{\omega}_{r}$

The brackish water is purified with the RO module and the relation between RO module variables can be written as mentioned in the table below:

$Q_{w}-Q_{b}-Q_{P}=0$

$C_{w} Q_{w}-C_{b} Q_{b}-C_{P} Q_{P}=0$

$Q_{p}=\left(P_{w}-P_{o s}\right) C_{R O} A$

$P_{o s}=R_{o s}\left(\frac{C_{b}+C_{w}}{2}\right)$

The Eq. (9) is the Water mass balance law [12], The Eq. (10) is the Salt mass balance law [12], The Eq. (11) is related to the RO membrane permeate flux [4,17] and the Eq. (12) is the Osmosis pressure relation [17].

The brackish water has a TDS less than 1000 and the RO pressure is less than 40bar [9]. The system parameters for this article are calculated based on the [9] and presented in Table 2.

Table 2: Parameters Definition for brackish desalination

\begin{tabular}{lll}
\hline Variable & Description & Value \\
\hline $\mathrm{Jr}$ & Rotor Moment of Inertia & $38 \mathrm{~kg} \cdot \mathrm{m}^{2}$ \\
$\mathrm{Br}$ & Rotor damping & $0.38 \mathrm{~N} \cdot \mathrm{m} . \mathrm{s} / \mathrm{rad}$ \\
$\mathrm{Dp}$ & Hydraulic pump geometric displacement & $22.5 \mathrm{CC}$ \\
$\mathrm{Dm}$ & Hydraulic motor geometric displacement & $4 \mathrm{CC}$ \\
$\mathrm{Dw}$ & Water pump geometric displacement & $28 \mathrm{CC}$ \\
$\mathrm{Cro}$ & RO module permeability & $98.5 \times 10^{-6}$ \\
$\mathrm{~A}$ & RO module Area & $25.2 \mathrm{~m}^{2}$ \\
$\mathrm{Ros}$ & Osmosis pressure constant for salt at 25 C & 0.7835 \\
\hline
\end{tabular}

The sea water has a TDS of about 35000 and the RO pressure is about 80 bar [9]. There is a significant energy waste in the pressurized brine flow.
To increased system efficiency, a Pressure exchanger for energy recovery from brine flow is used [18]. The availability of this module is more than $90 \%$ and the economic aspect of it is discussed in [19]. This device is very light (its dynamics are neglected compared to the wind turbine dynamics) and may have an efficiency of more than $90 \%$ and decrease the energy consumption of the RO system up to $40 \%$ [9].

The Desalination wind turbine concept for seawater is presented in Fig.3. In this configuration, The RO system model is changed. The relation for the system variables can be written as follows:

$Q_{w}+Q_{r}-Q_{b}-Q_{P}=0$

$C_{w}\left(Q_{w}+Q_{r}\right)-C_{b} Q_{b}-C_{P} Q_{P}=0$

$Q_{p}=\left(P_{w}-P_{o s}\right) C_{R O} A$

$Q_{r} P_{r}=Q_{b} P_{b} \eta_{r e c}$

The system specification for seawater desalination is calculated [9] and presented in Table 3.

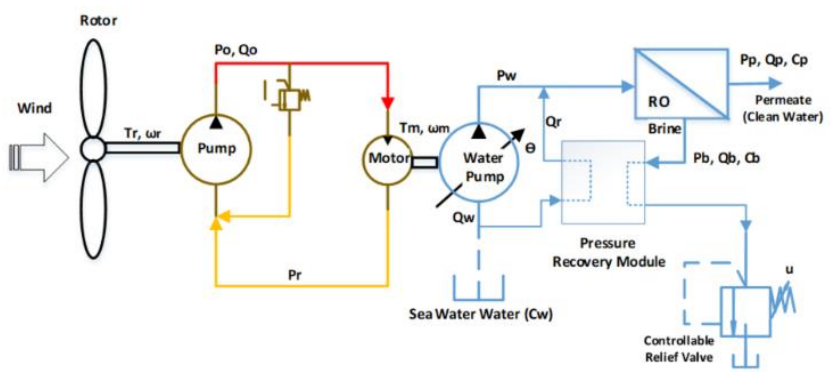

Figure 3: Desalination Wind Turbine Model for sea water

Table 3: Parameters Definition for seawater desalination

\begin{tabular}{lll}
\hline Variable & Description & Value \\
\hline Dw & Water pump geometric displacement & $8 \mathrm{CC}$ \\
A & RO module Area & $10.5 \mathrm{~m}^{2}$ \\
ๆrec & Efficiency of Recovery module & 0.9 \\
\hline
\end{tabular}

The Eq. (14) is the Water mass balance law [5], The Eq. (15) is the Salt mass balance law [5], The Eq. (16) is related to the RO membrane permeate flux $[4,17]$ and Eq. (17) is the energy balance relation for the recovery energy module. This module has a very fast response and its dynamics can be neglected [9].

\section{Steady State Analysis for Brackish water desalination}

For assessment of the Desalination Wind Turbine concept, a steady state condition of the system for brackish water desalination is calculated from Eq. (9). The right side of this equation is set to zero and the nonlinear equation is solved for different wind speed, from cut in $(3 \mathrm{~m} / \mathrm{s})$ to cut out $(18 \mathrm{~m} / \mathrm{s})$.

In this system, the water pressure $(P \mathrm{w})$ can be tuned by a controllable relief valve. If the $P \mathrm{w}$ is high, the water flow is decreased (Energy balance) and as a consequence, the permeate flow is decreasing. If the $P w$ is low, the difference between water pressure and osmosis pressure is low, then the permeate flow is decreasing again. Therefore, there should be an optimum 
$P w$ for maximum permeate flow. The Eq. (9) for steady state is solved and optimized $P w$ is calculated.

The aerodynamic power, Pitch angle and rotor speed for brackish water desalination system is plotted in the Fig. 4. The wind turbine rotor starts to rotate from $3.5 \mathrm{~m} / \mathrm{s}$ wind velocity (Cut-in). The rated power is $3600 \mathrm{~kW}$ at $7.5 \mathrm{~m} / \mathrm{s}$ wind velocity. In this band, which is called Zone II, the pitch angle is zero and rotor speed should be controlled to be increased from $12 \mathrm{rad} / \mathrm{sec}$ to the $15 \mathrm{rad} / \mathrm{sec}$, linear with wind velocity, to have the best aerodynamic performance. In the Zone III, from the rated to the cut-out wind velocity, the rotor speed is constant and the pitch angle is increased to regulate rotor speed.
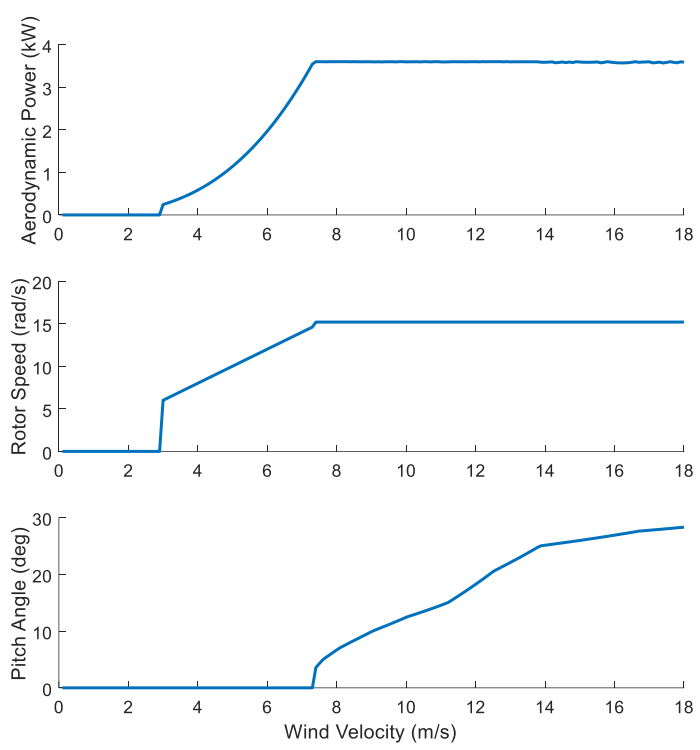

Figure 4: Wind Turbine variables

The hydraulic oil pressure, hydraulic oil flow and the motor angular is shown in Fig. 5. By increasing rotor speed in Zone II, the oil flow is increased from 20 to $50 \mathrm{lit} / \mathrm{min}$. In order to track the best aerodynamic performance conditions (rotor speed), the water pump angle should be increased Fig. 6. Then the oil pressure increased consequently.

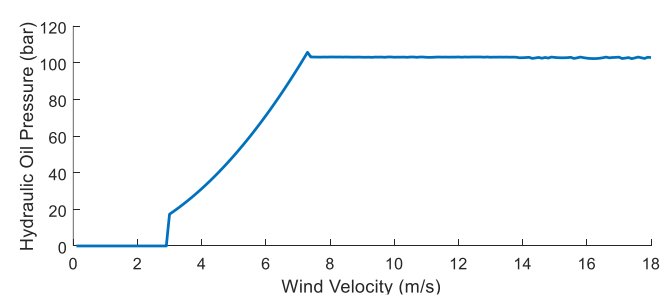

Figure 5: The oil pressure

The optimum water pressure curve is shown in Fig. 6. The permeate water flow is calculated based on Equations (10) to (13) as shown in Fig.6. The important parameter for a classical wind turbine is the annual power production. For this concept, the Annual permeate Water Production (AWP) is important. The AWP for different annual wind speed based on the Rayleigh distribution function is calculated similar to annual power production [20] and reported as in Table 4. Water pressure optimization can increase the annual water production by about $8 \%$, when the annual wind speed is $3 \mathrm{~m} / \mathrm{s}$ less than the rated wind speed, which is notable. But this optimization improvement, is decreased if the annual wind speed (compare to the wind turbine rated wind speed) is increased.

Annual Water Production $=8760 \times \int_{V w(\text { Cut }- \text { in })}^{V w(\text { Cut-out })} Q_{p} P_{R a y .}\left(V_{w}\right) d V_{w}$

$P_{\text {Ray }}$ is the Rayleigh probability function and 8760 is the hours in one year.

Table 4: Annual Water Production

\begin{tabular}{llllll}
\hline Annual Wind velocity $(\mathbf{m} / \mathbf{s})$ & $\mathbf{5}$ & $\mathbf{6}$ & $\mathbf{7}$ & $\mathbf{8}$ & $\mathbf{9}$ \\
\hline AWP $\left(\mathrm{m}^{3}\right)$ for Pw $=18$ bar & 2936 & 3755 & 4363 & 4759 & 4963 \\
AWP $\left(\mathrm{m}^{3}\right)$ for Optimized Pw & 3165 & 3953 & 4530 & 4899 & 5081 \\
AWP Increase $(\%)$ & 8 & 5 & 4 & 3 & 2 \\
\hline
\end{tabular}
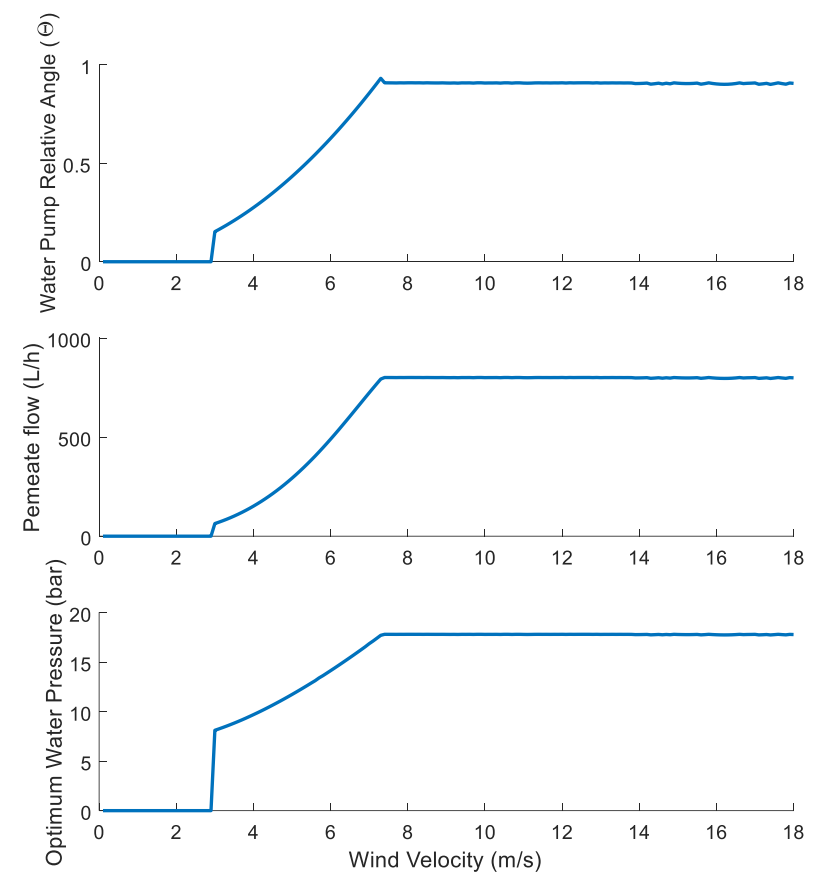

Figure 6: Brackish Desalination system variables

The steady state condition of the system for sea water desalination is calculated from Eqs. $(9,14-17)$ and Table 3 parameters, similar to the brackish water desalination. The main changes between the two systems are the permeate water flow rate and the annual water production. The permeate water flow is calculated based on Eqs.14 to 17 as shown in Fig. 7.

The AWP for different annual wind speed based on the Rayleigh distribution function is calculated and reported as in Table 5. In this simulation, the recovery module can increase the permeate production of about $46 \%$, which is decreased with the increase of the annual wind speed, slightly.

Table 5: Annual Water Production

\begin{tabular}{clllll}
\hline Annual Wind velocity $(\mathbf{m} / \mathbf{s})$ & $\mathbf{5}$ & $\mathbf{6}$ & $\mathbf{7}$ & $\mathbf{8}$ & $\mathbf{9}$ \\
\hline AWP $\left(\mathrm{m}^{3}\right)$-without recovery system & 2346 & 3001 & 3487 & 3805 & 3968 \\
AWP $\left(\mathrm{m}^{3}\right)$ - with recovery system & 3451 & 4378 & 5060 & 5502 & 5726 \\
AWP Increased $(\%)$ & 47 & 46 & 45 & 45 & 44 \\
\hline
\end{tabular}




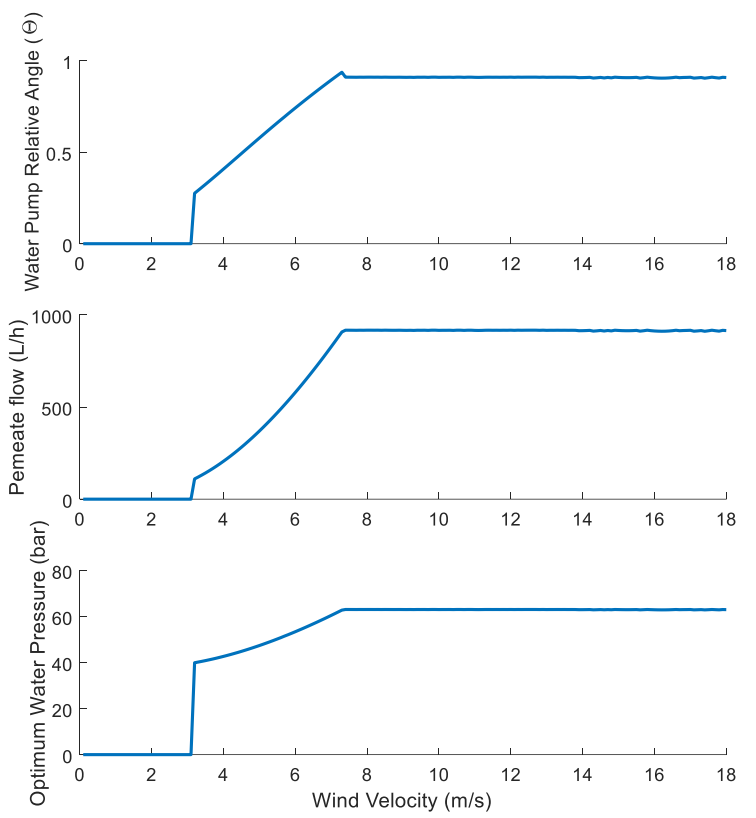

Figure 7: Seawater Desalination system variables

\section{Controller Structure Design}

For wind turbine, the capability of Maximum Power Point Tracking (MPPT) is very important. For the Desalination Wind Turbine Concept, the oil pressure can be measured easily and it has a relation with a rotor angle Fig. 8. Therefore, it can be used for MPPT. Instead of the power measurement of the wind turbine generator, the Rotor speed reference can be calculated from the oil pressure measurement and the command signal is sent to the water pump to set the relative angle.

As it is mention in the previous section, to have the maximum permeate flow, similar to MPPT for power production, this system needs a control system for Maximum Permeate Flow Tracking (MPFT). Refer to the Figs. 4 and 8, the $P w$ has a relation with the rotor speed, which is plotted in Fig. 9. For MPFT, a reference $P w$ is calculated based on this Figure and a new control loop is added to the system. The block diagram of the closed loop system is shown in Fig. 10.

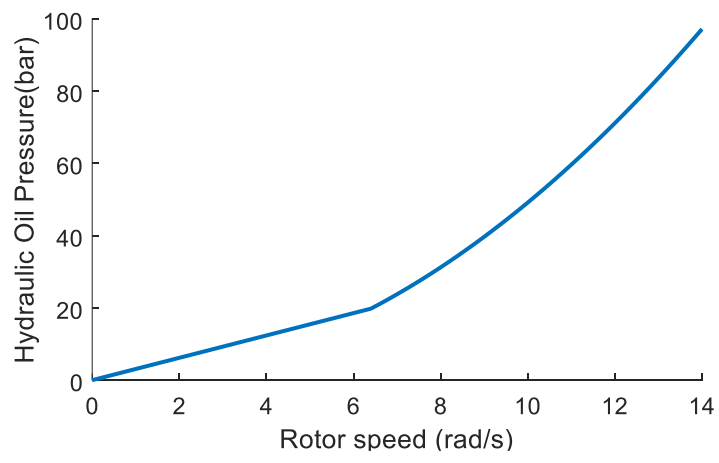

Figure 8: The Hydraulic Oil Pressure curve for MPPT

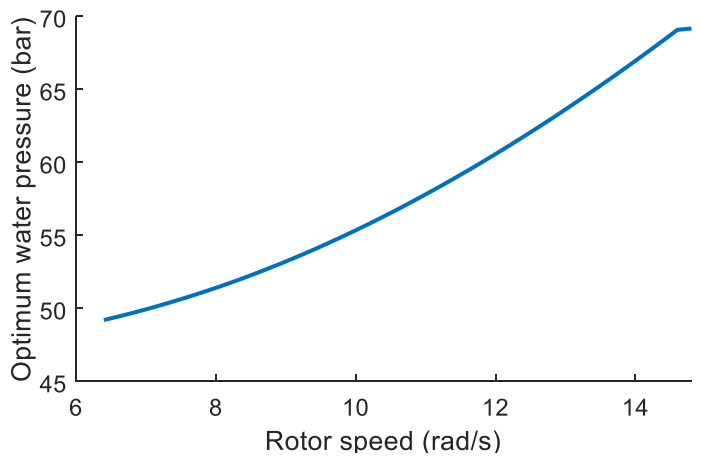

Figure 9: The optimum water Pressure for MPFT

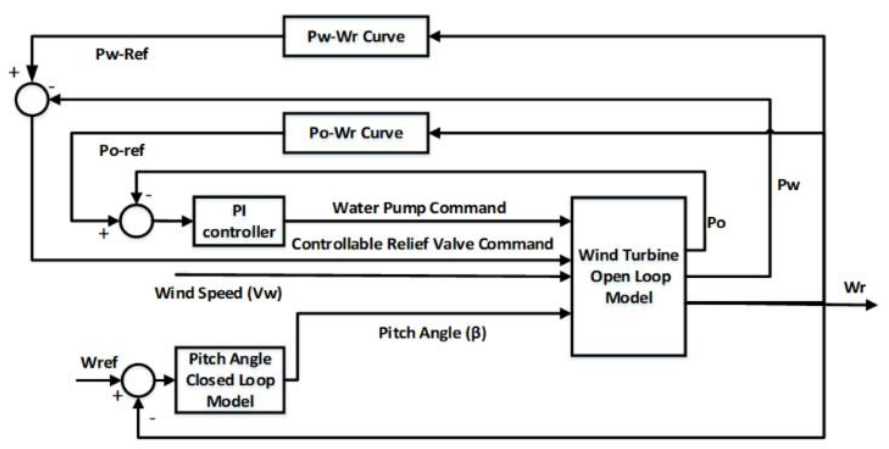

Figure 10: The Closed loop Structure for Desalination Wind Turbine Concept

It has three controller blocks: Pitch controller for rotor speed regulation and Oil pressure controller for MPPT and Water pressure for MPFT. The algorithm for controller tuning is as follows:

- Step 1: The pitch angle controller strategy is similar to what has been assigned by [16], is chosen. This is a PID schedule gain controller. The controller gains are determined to place the poles in the desire position. More details are described in [16].

- Step 2: the oil pressure controller for seawater system is designed as follows (Laplace Domain):

$P I=2 \times 10^{-6}\left(1+\frac{0.25}{s}\right)$

The PI parameters are set such that the closed loop system tracks the reference Po and has a fast response to the sudden wind changes to prevent the rotor over speed (speed more than $180 \mathrm{rev} / \mathrm{min}$ ) does not happen in the ZONE II.

- $\quad$ Step 3: the water pressure controller for seawater system is designed as follows (Laplace Domain):

$P I=1 \times 10^{-6}\left(1+\frac{0.2}{s}\right)$

The PI parameters are set such that the closed loop system tracks the reference $\mathrm{Pw}$ and does not make a disturbance or vibration for the Oil pressure closed loop in the ZONE II. 


\section{Results}

To analyzed the dynamic performance of the presented desalination wind turbine, the system is simulated in the MATLAB software [21], based on the nonlinear equations (Section 3). The system should be stable and has not significant overshoot when the wind speed is changed and in the presents of the wind turbulence.

The sea water closed loop system response to the wind variations is plotted in Figs. 11 and 12. In Fig. 11, the wind turbine response to the wind variation is presented. The wind velocity is changed from 4.5 to $11.5 \mathrm{~m} / \mathrm{s}$, with a Sine wave shape. It is in the Zone II and III (Section 3). The pitch controller, oil pressure controller, and water pressure controller are active. The maximum oil pressure is set to 120 bar, after it, this subsystem is saturated (the relief valve will be activated). When the rotor speed is more than $145 \mathrm{rpm}$ (rated rotor speed) the pitch controller is activated to regulated rotor speed. The pitch angle is increased at its maximum rate $(10 \mathrm{deg} / \mathrm{sec})$. By increasing the wind speed up to $9 \mathrm{~m} / \mathrm{s}$, the water pressure is maximized (saturated, at 79 bar). Then the oil pressure is maximized (saturated at 120 bar). In this condition (wind speed between 7.5 to $9 \mathrm{~m} / \mathrm{s}$ ) both pitch control loop and oil pressure control loop are active. When the oil pressure is maximized, the rotor speed has the maximum overshoot (about 16\%). After this point, the pitch controller has more effect and the rotor speed is reduced. The system behavior shows the stability and performance of the Desalination Wind Turbine concept for MPPT and MPFT. In all wind speed the water pressure controller optimized the water pressure for maximum permeated flow and when the oil pressure is saturated, it reaches to its maximum point
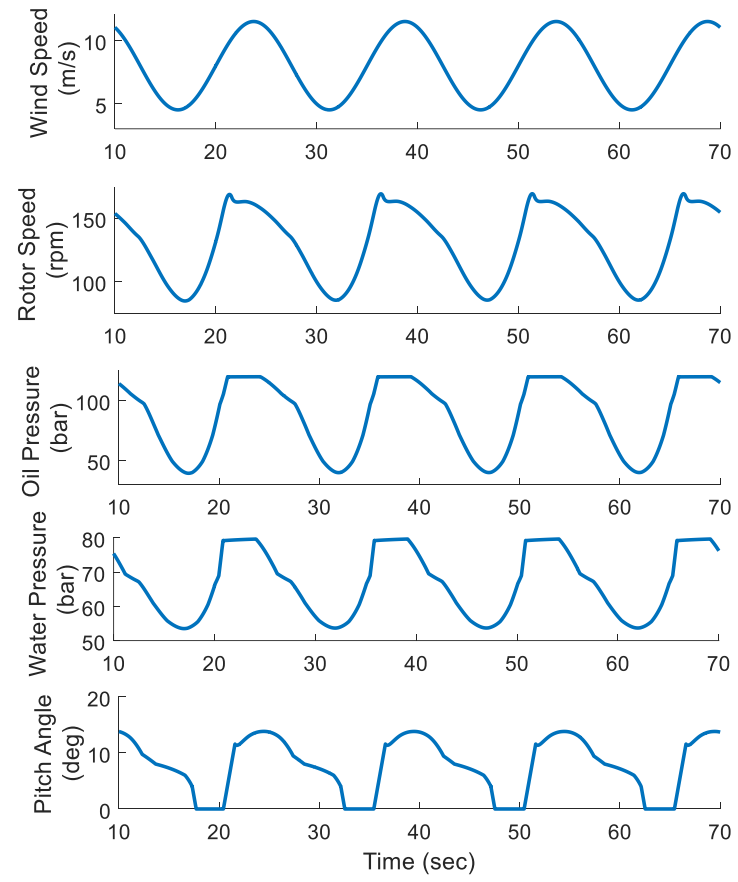

\section{Figure 11: Response of the Wind Turbine to the Wind speed change}

The response of a wind turbine to the wind turbulence is a key factor to evaluate the control loop performance. In Fig. 12, the wind turbine response to the wind turbulence is presented. The wind velocity is changed from 3.5 to $9.5 \mathrm{~m} / \mathrm{s}$ to check the ability of the oil pressure and water pressure controller to rotor speed tracking (Zone II). The maximum overshoot of the rotor speed is $16 \% \mathrm{rpm}$, when the water pressure is saturated (at $42 \mathrm{nd}$ second).

According to the simulation results, oil pressure or water pressure saturation causes the rotor over speed in the presence of the sudden wind speed change. Therefore, using oil and water accumulator with pre-charge more than rated pressure that can store energy, may reduce the rotor speed overshoot. This investigation will be performed in the future study.
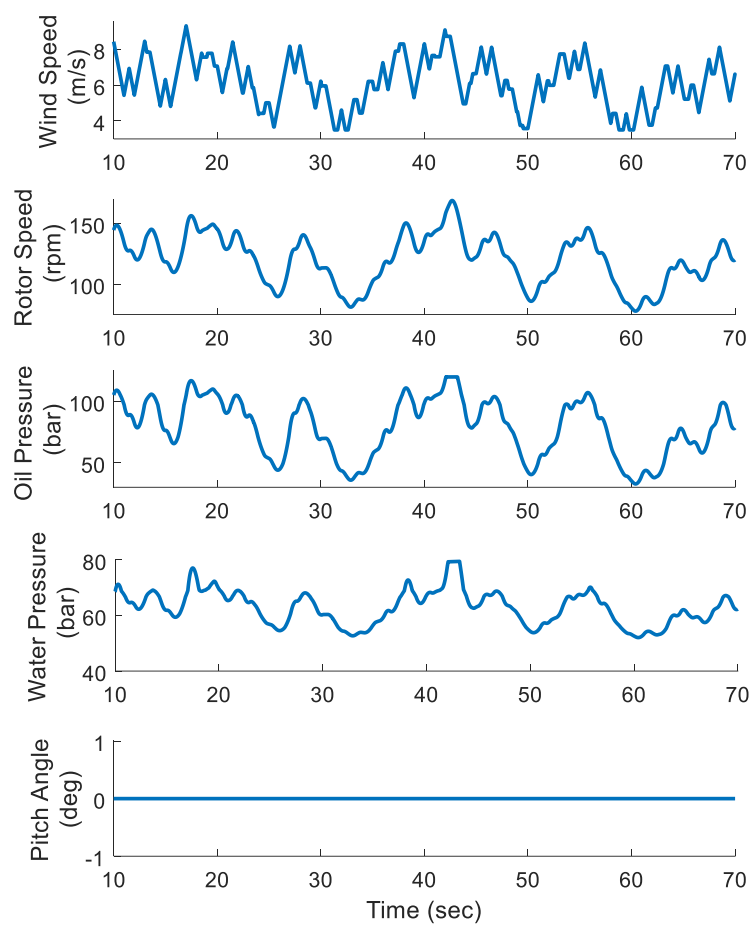

Figure 12: Response of the Wind Turbine to the Wind Turbulence

\section{Conclusion}

In this article a novel concept for wind turbine empowered RO desalination system is introduced. The nonlinear equations of the system are derived. The pressure of the RO unit is optimized for maximum permeated flow. The steady state performance and dynamic behavior and is analyzed for seawater and brackish water desalination. For a similar condition (annual wind speed $6 \mathrm{~m} / \mathrm{s}$ and without the energy recovery module) the annual permeate for brackish water desalination is about $25 \%$ more than seawater desalination.

Minimizing the energy usage is the goal of this concept. Therefore, the Pressure recovery module is used to minimize the energy demand for seawater pumping. This module can be increased the permeate flow up to $47 \%$, which is significant. With this module for sea water, the annual permeate for seawater water desalination is $16 \%$ more than brackish water desalination without this module.

This concept, has a lower component and cost, compared to the Wind turbine with electricity output and a RO system. The value proposition of this concept is highlighted in the offshore wind turbine, in which the weight of nacelle and tower is very important.

The next contribution of this article is the introduction of the Maximum Permeate Flow Tracking, which can be increased the output of the system about $10 \%$, especially for area with lower wind speed, compared 
to the wind turbine rated wind speed. The concept can also be used for Photovoltaic system, which empowers desalination plants.

For this concept, an advanced control system is introduced that can have a good response to the wind turbulence. In this system a simple measurement of the oil pressure is used for Maximum Power Point tracking which is more reliable compared to classical solutions. In addition, this concept can be used for stall wind turbine.

The controller optimization and modeling details of the system can be performed in the future study.

\section{REFERENCE}

[1] Ahmed Alkaisi, Ruth Massad, Ahmad Sharifian-Barforoush, "A review of the water desalination systems integrated with renewable energy", Energy Procedia, 2017, pp 268-274

[2] Seyedsaeid Ahmadvand, Behrooz Abbasi, Babak Azarfar, Mohammed Elhashimi, Xianh Zhanh, Bahman Abbasi, "Looking beyond energy efficiency: An Applied review of water desalionation technologies and an introduction to Capillary-Driven Desalination”, Water, pp1 -30, 2019

[3] Muhammad Wakil Shahzad, Mumammad Burhan, Doskhan Ybyraiymkul, Kim Choon Ng, "Desalination Process efficiency and future road map", Entropy, pp1-14, 2019

[4] Hassan A.Arafat, "Desalination sustainability", Elsevier, pp 150-170 ,2017

[5] Jane Kucera, "Reverse Osmosis", Wily, $2^{\text {nd }}$ Edition, 2015

[6] Karen E. Thomas, "Overview of village Scale, Renewable energy powered desalination', NREL, 1997

[7] Gnaneswar Gude , "Renewable Energy Powered Desalination Handbook", Elsevier Inc, 2018

[8] Markus Forstmeier, Fredrik Mannerheim, Frenando D'Amato, Minesh Shah, Yan Lui, Michael Baldea, Albert Stella, "Feasibility study onpowered desalination", Desalination, 2007

[9] Niskayuna, "Integrated Wind Energy/ Desalination System", NREL, 2006

[10] Tony burton, Nick Jenkins, David Sharpe, Ervine Bossanyi, "Wind Energy Handbook", Wiley, 2011

[11] Limin Yang, Zhiyu Jiang, Zhen Gao, Torgeir Moan, "Dynamic analysis of a floating Wind Turbine with a hydraulic transmission system", Energy Procedia, 2014, pp 44-55

[12] Donap Rajanbhandharaks, "Control of Hydrostatic Transmission Wind Turbine", Master of science thesis, Department of Electrical Engineering, San Jose State University, 2014

[13] Yin Zhang , Xiangdong Kong ,Li Hao, Chao Ai, “ Controls of hydraulic wind turbine", EDP Sciences, 2016, pp 1-4

[14] Niels Fredrik Boudewijin, "On the Application of Fluid Power Transmission in Offshore Wind Turbines", PhD Thesis, Delf University, 2013

[15] MacKay, Gary Ancaster, Vander Straeten, Ronald Guelph, "Wind turbine with hydrostatic transmission", European Patent Application, 2017 [16] Arash Hatami, Behnam Moetakef-Imani, "Innovative adaptive pitch control for small wind turbine fatigue load reduction", Mechatronics, 2016, pp 1-9

[17] Lewabrane, "Principle of Reverse Osmosis Membrane Separation", NakXess Engineering Chemistry, 2013

[18] Richard L. Stover, "Energy Recovery Device performance analysis", Water Middle East, 2005

[19] "The Availability advantage of reliable energy recovery technologies",
Energy Recovey Inc, 2011

[20] Gilbert M. Masters, "Renewable and efficient electrical Power Systems", Wily, 2004

[21] "MATLAB and Simulink Toolbox Release 2016a", The Math Works, Inc., Natick, Massachusetts, United States. 